\title{
A morte de Osama Bin Laden e suas implicações para o futuro da Al-Qaeda*
}

\author{
Bruno Mendelski de Souza ${ }^{1}$
}

\section{Resumo}

O presente artigo objetiva empreender uma investigação histórico-sociológica da Al-Qaeda, analisando seus ideais constitutivos, bem como sua evolução histórico- operacional até a atualidade. Procuramos identificar e traçar as possíveis tendências de comportamento da organização sem a presença de seu principal líder, Osama bin Laden e concluímos que a Al-Qaeda, na contemporaneidade, atua mais como fonte de inspiração para grupos radicais islâmicos do que como uma organização estrita, e nesse sentido a morte de Bin Laden pouco enfraquece a operacionalidade do grupo.

Palavras-chave: Al-Qaeda. Pensamento islâmico radical. Osama bin Laden.

\section{Introdução}

O mundo foi pego de surpresa no dia $1^{\circ}$ de maio de 2011 com a notícia da morte de Osama bin Laden pelo exército norte-americano, no Paquistão. O líder e fundador do grupo Al-Qaeda era considerado pelos EUA o seu inimigo público número 1, em virtude de ser responsabilizado pelos atentados terroristas de 11 de setembro de $2001 .^{2}$

* Recebido em 30.05.2011.

Aprovado em 02.08.2011

1 Bacharel em Relações Internacionais pelo Centro Universitário Unilasalle (2009), Mestrando em Relações Internacionais pela UFRGS (2010) e Bolsista por produção da Capes; bruno_mendelski@yahoo.com.br

2 Considerado o maior atentado terrorista da História, os eventos de 11 de setembro deixaram cerca de três mil mortos quando dois aviões comerciais atingiram o World Trade Center em Nova Iorque; um avião atingiu o Pentágono e outro caiu em uma área rural, na Pensilvânia. 
Desde o início da década de 1990, Bin Laden, juntamente com a Al-Qae$\mathrm{da}$, vem realizando ataques a alvos norte-americanos e a seus aliados ao redor do mundo. A busca pelo extremista saudita se intensificou no pós-11 de Setembro, passando a integrar a doutrina político-militar denominada "Guerra ao Terror", criada pelo governo dos EUA para combater a Al-Qaeda e demais agremiações consideradas terroristas em âmbito global. Entre suas ações, destacam-se as Guerras do Afeganistão (2001) e do Iraque (2003).

Depois da morte de Bin Laden, algumas indagações parecem surgir naturalmente: quais seriam as principais implicações desse acontecimento para o futuro da Al-Qaeda? Como irá reagir a organização sem o grande guia? As operações de ataque por parte do grupo serão enfraquecidas ou intensificadas?

Tais questionamentos, em razão da complexidade do tema e do recente período em que foram feitos, demonstram-se impossíveis de serem respondidos nesse primeiro momento. Nesse sentido, procuramos, a partir de uma investigação histórico-sociológica da Al-Qaeda, identificar e traçar as possíveis tendências de comportamento para a organização nos próximos anos, sem a presença de seu grande líder.

Dentro do estudo que apresentaremos sobre o Al-Qaeda, julgamos importante destacar que houve, ao longo do tempo, uma mudança no formato funcional da organização. O grupo, até a invasão do Afeganistão pelos EUA em outubro de 2001, estava dependente de um território para suas atividades operacionais, que eram geridas de forma mais centralizada. Com o novo conflito em solo afegão, a Al-Qaeda teve sua infraestrutura destruída. Essa situação fez com que a organização de Bin Laden atuasse de forma clandestina e descentralizada. A partir de então, ela age mais como ideologia para novos militantes islâmicos do que como uma organização rígida e funcional.

Neste artigo, apresentaremos, primeiramente, a origem e o contexto histórico da formação da Al-Qaeda. Posteriormente, analisaremos o papel de Osama bin Laden dentro da organização. Por fim, examinaremos o modo de atuação da Al-Qaeda no cenário internacional depois da ofensiva político-militar "Guerra ao 
Terror", dos EUA e aliados. Concluiremos delineando as possíveis decorrências da morte de Bin Laden para o futuro estratégico da Al-Qaeda.

\section{Origem e a ideologia da Al-Qaeda}

O surgimento da $\mathrm{Al}$-Qaeda está intimamente conectado a duas questões primordiais. A primeira refere-se à influência da doutrina islâmica radical sob o pensamento daqueles que são considerados os fundadores da organização: o palestino Abdullah Azzam e o saudita Osama bin Laden. A segunda diz respeito aos principais acontecimentos geopolíticos do Oriente Médio e do Afeganistão, que ocorreram entre o final da década de 1970 e o início da década de 1990, sobretudo a invasão soviética ao Afeganistão (1979-1989) e a Guerra do Iraque (1991).

O teólogo muçulmano Abdullah Azzam (1941-1989) recebeu forte inspiração das ideias radicais do egípcio Sayyd Qutb (1906-1966) e da Irmandade Muçulmana $^{3}$ (da qual fazia parte). Qutb desenvolveu o conceito de jahiliyya (estado de ignorância anterior à revelação do Islamismo a Maomé) para designar as sociedades mulçumanas que não se encontravam sob um governo islâmico. O egípcio acreditava que era necessário destruir a jahiliyya, como fizera o Profeta, para edificar, sobre seus escombros, o Estado Islâmico (KEPEl, 2003, p. 58). Nessa situação, a punição para aqueles que compactuavam com a jahiliyya poderia ser a condenação à morte.

Azzam foi o mentor de Bin Laden e o responsável pela composição, formatação e objetivos da Al-Qaeda, podendo ser considerado seu pai ideológico (GUNARATNA, 2003, p. 72). As ideias de Azzam são imprescindíveis para um bom entendimento da dinâmica da Al-Qaeda atualmente. A atuação da Al-Qaeda por meio de organizações associadas e o alto valor simbólico e operacional das declarações de seus líderes (que inspiram o surgimento de novos grupos islâmicos) são mecanismos teorizados por Azzam durante seu envolvimento no conflito do Afeganistão.

\footnotetext{
3 Organização islâmica reformista, criada em 1928 no Egito por Hassan al-Banna que se opõe às tendências seculares das nações islâmicas. Ainda está em atividade atualmente mas, no Egito, como em muitos países, é considerada um grupo clandestino.
} 
Durante a invasão soviética no Afeganistão, Azzam colocou em prática seus

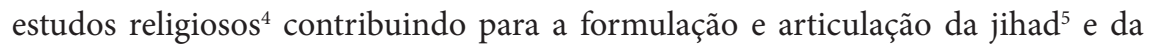
mobilização de afegãos e árabes que comporiam as fileiras mujaheddins ${ }^{6}$ os quais lutariam contra as tropas soviéticas (AMORIM, 2008, p. 73-74). Azzam pregava que a jihad nessa luta contra os soviéticos era uma obrigação de todo mulçumano.

Na guerra do Afeganistão, Azzam conheceu o milionário saudita Osama Bin Laden, que nasceu em 30 de junho de 1957 em Riad, oriundo de uma rica ${ }^{7}$ e influente família saudita, que enriquecera por meio da atividade da construção civil. Na faculdade de Economia da Universidade de Jedá, Bin Laden iniciou seus contatos com as ideias islâmicas radicais, onde "frequentou aulas de estudos islâmicos lecionados por Muhammad Qutb, irmão de Sayyid Qutb, e por Abdullah Azzam, tendo ambos exercido sobre ele uma forte influência” (GUNARATNA, 2004, p. 89).

No início dos anos 1980 Bin Laden parte para o Paquistão, a fim de participar do processo de gerenciamento da resistência afegã. Juntamente com o seu ex-professor Azzam, Bin Laden funda em 1984 o Maktab al Kidmay lil Mujahidin al-Arab (MAK), ou “Gabinete Afegão de Serviços”, que tinha como objetivo recrutar, doutrinar e treinar milhares de jovens árabes e muçulmanos de toda parte do mundo, que se voluntariavam para tomar parte no conflito afegão.

No MAK, Azzam desenvolveu suas ideias de jihad e de movimento vanguardista do Islamismo, que posteriormente serviriam de base para a Al-Qaeda. Na obra Join the Caravan, Azzam apresenta conceitos que futuramente guiarão o pensamento de Bin Laden e da Al-Qaeda, como o da obrigatoriedade da jihad e da necessidade de obediência ao líder:

4 Bacharel em estudos islâmicos na Jordânia e Doutor em Jurisprudência islâmica no Egito.

5 Termo árabe que significa luta em favor de Deus; aplicada tanto para a busca do autocontrole quanto para a islamização da sociedade e a luta armada contra os infiéis. Por ser um conceito muito amplo, jihad não possui aceitação universal em relação à definição dada acima.

6 Termo árabe que significa "Guerreiro da Jihad".

7 A fortuna estimada após a morte acidental (em um helicóptero) do pai de bin Laden em 1968, era estimada em 11 bilhões de dólares (KEPEl, 2003, p. 467). 
Quando o inimigo penetra na terra dos mulçumanos, a jihad torna-se obrigatória para todos, [grifo nosso]. [...] Quando a jihad torna-se obrigatória, não é necessária a autorização dos pais. [...] A jihad é a obrigação de uma vida [grifo nosso]. [...] A jihad é atualmente obrigatória para todos, em pessoa e pela riqueza, em todos os locais ocupados pelos infiéis. Mantém-se obrigatória até que cada pedaço de terra que antes tinha sido islâmica tenha sido recuperada. [...] A jihad é um ato coletivo de adoração, e cada grupo deve ter um líder. A obediência ao líder é uma necessidade da jihad, e por isso um indivíduo deve condicionar-se invariavelmente a obedecer ao líder [grifo nosso]. [...]. (1987, s. 1, apud GUNARATNA, 2004, p. 177).

Segundo Roy (2004, p. 295), Azzam "concluiu que a única jihad legítima seria aquela que motivasse toda a $u m m a h^{8}$ e escolheu a resistência afegã contra a invasão soviética como o modelo exemplar". Da mesma forma que a jihad era uma obrigação para todo muçulmano, Azzam também acreditava na necessidade da criação de uma nova vanguarda dentro do pensamento do mundo muçulmano. Essa vanguarda deveria ser guiada pelos ideais islâmicos mais puros e servir de exemplo para toda a sociedade muçulmana. Ela seria a base sólida (Al-Qaeda al Sulbah em árabe) para esse novo despertar do povo islâmico. Para Gunaratna (2004, p. 95), Azzam "imaginou a Al-Qaeda como uma organização que canalizaria as energias dos mujaheddins para a luta a favor dos muçulmanos oprimidos em todo o mundo", uma "força islâmica de reação rápida".

Segundo o próprio em artigo publicado no jornal afegão Al-Jihad:

Qualquer princípio precisa de uma vanguarda para o levar para frente e, enquanto concentra o seu caminho na sociedade, empreende pesadas tarefas e enormes sacrifícios. Não existe ideologia, nem terrestre e nem celeste que não necessite de uma tal vanguarda que lhe dê tudo o que possui de modo a alcançar a vitória de sua ideologia. Transporta a bandeira por todo o interminável e difícil caminho até alcançar o seu destino na realidade da vida, pois Alá decidiu que o deveria fazer e dar-se a conhecer. Esta vanguarda é a Al-Qa'idah al Sulbah para a sociedade desejada (1988, p. 46 apud GUNARATNA, 2004, p.72, grifo nosso).

8 Termo árabe que exprime a ideia de comunidade dos muçulmanos, tanto no sentido de fiéis quanto no sentido nacional. 
Enquanto teorizava sobre o que viria a ser a Al-Qaeda, Azzam, juntamente com Bin Laden, seguia coordenando o Gabinete Afegão de Serviços, no qual desenvolveram, durante todo o período da invasão soviética no Afeganistão, dezenas de campos de treinamento e casas de hóspedes que serviam para acolher os voluntários que chegavam para a luta, além de sistemas de cavernas e túneis encravados nas montanhas da divisa do Afeganistão e Paquistão. Toda essa infraestrutura do MAK viria a ser amplamente utilizada pela organização que iria ser criada no pós-guerra, a Al-Qaeda.

Durante o período de conflito, Bin Laden popularizou-se entre a resistência afegã por realizar generosas doações financeiras à causa e por integrar pessoalmente os fronts de batalha. Para Gunaratna (2003, p. 95-96):

[...] a filantropia de Osama tornou-o ainda mais popular no Afeganistão. Apesar de vir de uma família privilegiada, a sua dedicação à jihad, a sua humildade e simplicidade e a sua capacidade para ajudar e para comunicar-se com os soldados no terreno atraíram os mujaheddins.

No final dos anos 1980 a riqueza, influência e coragem de Osama o transformam no líder natural dos mujaheddins, enquanto Azzam popularizava a ideia de jihad e desenvolvia o conceito daquilo que viria a ser a Al-Qaeda. Nesse período, Bin Laden se aproxima da facção egípcia do MAK, mais radical e liderada pelo médico Ayman al-Zawahiri, que pregava o uso extremo da violência e a adoção de técnicas terroristas; ao contrário de Azzam.

Em 1989, em um misterioso atentado à bomba, Azzam é morto. Os eventos que se seguem impulsionam a liderança militar e religiosa de Bin Laden: os soviéticos são derrotados no Afeganistão e, com a ausência de Azzam, o saudita colhe sozinho os louros dessa vitória e Zawahiri torna-se o seu braço direito e médico particular.

\section{0 início da Al-Qaeda}

Após a derrota dos soviéticos no Afeganistão, Bin Laden reagrupa parte dos combatentes mujaheddins, aproveita-se da estrutura e dos recursos do MAK e fun- 
da a Al-Qaeda, para agora combater nos diversos fronts onde haja grupos islâmicos envolvidos. Nesse primeiro momento, a Al-Qaeda atuou direta ou indiretamente "na Caxemira, Chechênia, Mindanau, Tadjiquistão, Uzbequistão, Somália, Malásia, Indonésia, Geórgia, Nagorno-Karabakh, Azerbaijão, Iêmen, Argélia e Egito” (GUNARATNA 2004, p. 74).

Em agosto de 1990 o Iraque invade o Kuwait e dá início à Guerra do Golfo. Osama prontamente oferece ao governo da Arábia Saudita a ajuda de seus serviços militares para combater o país de Saddam Hussein. A Arábia Saudita nega e autoriza que tropas norte-americanas utilizem o território saudita durante as operações de guerra, assegurando a Bin Laden que as mesmas sairiam do local após o término do conflito. Porém, as tropas norte-americanas permanecem na Arábia Saudita, o que foi considerado uma traição por Bin Laden. A partir de então, Osama rompe com o governo saudita e começa uma campanha verbal e operacional para derrubá-lo.

Ao mesmo tempo em que se expandia internacionalmente, a Al-Qaeda via seu berço político-militar - o Afeganistão - tornar-se fortemente instável em razão da guerra civil causada pelo término do conflito com a União Soviética. A instabilidade no Afeganistão era prejudicial à infraestrutura que a Al-Qaeda havia herdado do MAK no país. Paralelamente, Osama começa a ser cortejado pelo presidente do Sudão, Hassan al-Turabi, para deslocar suas bases para esse país. A necessidade de um território amigo para poder gerenciar as atividades da Al-Qaeda e o desejo de al-Turabi de ter um aliado para os conflitos religiosos com o sul do Sudão, fizeram com que a Al-Qaeda transferisse sua infraestrutura para esse país em 1991.

Em solo sudanês, "Osama diversificou seus negócios e fundou cerca de trinta empresas; desde laboratórios de alta tecnologia até a engenharia civil" (GUNARATNA 2004, p. 107). Do mesmo modo que gerava riquezas para si, a Al-Qaeda também investia em ações de interesse para o Sudão, muitas vezes até executando o papel de governo, como na criação de pontes e estradas ${ }^{9}$ investimentos em várias áreas do país.

9 Destaca-se a construção da estrada de $1.200 \mathrm{~km}$ que liga a capital do país, Cartun, ao principal porto do Sudão. 
A alta rentabilidade de suas transações, aliada à estabilidade política e territorial no Sudão, fez com que a Al-Qaeda estruturasse e consolidasse suas fontes de financiamento. Ela também elaborou o seu sistema de células terroristas independentes e desenvolveu sua rede de contato e conexões com diversos outros grupos terroristas em torno de seu comando central. Para Amorim (2008, p. 83) “[...] foi no período do Sudão que a Al-Qaeda tornou-se a maior organização terrorista do planeta”.

Foi a partir de sua base no Sudão que a Al-Qaeda iniciou sua campanha de atentados terroristas. Em 1992, ocorre o primeiro ataque da organização, com a explosão de duas bombas em hotéis no Iêmen, que mataram dois australianos. Em fevereiro de 1993, ocorre o primeiro atentado ao World Trade Center nos EUA, por meio de uma explosão de um veículo no estacionamento do local, que objetivava gerar uma explosão capaz de danificar os alicerces da torre, e assim, derrubá-la. A explosão não sai como o planejado, mas deixa seis mortos e cerca de mil feridos.

A partir de 1994 a estadia da Al-Qaeda no Sudão começava a apresentar problemas. A grave situação econômica do país, somada ao congelamento dos bens de Bin Laden pelo governo saudita, enfraqueceram a condição econômica da Al-Qaeda. Países como o Egito e a Argélia (que percebiam Bin Laden como inspirador e apoiador de grupos radicais Islâmicos nesses países) começaram a pressionar o Sudão para que expulsasse Bin Laden e a Al-Qaeda de seu território. Percebendo que sua presença no Sudão estava se tornando insustentável, Bin Laden decide retornar a Al-Qaeda para o Afeganistão.

\section{0 retorno ao Afeganistão (1996-2001)}

Chegando ao Afeganistão, a Al-Qaeda estabeleceu uma aliança com o grupo radical islâmico Talibã ${ }^{10}$, que, na época, controlava cerca de $90 \%$ do território afegão. A organização de Bin Laden oferecia suporte financeiro e disponibilizava seus combatentes ao governo local. O Talibã respondeu concedendo à Al-Qaeda

\footnotetext{
${ }^{10}$ Organização político-militar criada pelo afegão Mohammed Omar, no inicio dos anos 1990, que defendia que o Afeganistão fosse governado segundo a lei islâmica.
} 
livre acesso a todo o território controlado pelo grupo, incluindo campos de treinamento, armamentos e outros equipamentos militares.

Durante o período em que esteve no Afeganistão, Bin Laden efetuou seus principais discursos, lançou oficialmente sua jihad contra o Ocidente e se tornou conhecido e influente no mundo. Nesses discursos, buscava legitimidade dentro do âmbito religioso, realizando citações ao Alcorão e classificando seus pronunciamentos como decretos religiosos oficiais ou fatwas. ${ }^{11}$ No entanto, Gunaratna (2004, p. 77) afirma que "[...] nenhuma das autoridades islâmicas reconhecidas (sunita ou xiita) consideram Osama bin Laden como um indivíduo legitimado para o fazer".

O primeiro grande pronunciamento ocorreu em agosto de 1996, intitulado "Declaração de Jihad contra os Americanos Ocupantes da Terra dos Dois Santuários Sagrados ${ }^{12 ”}$ :

Não é segredo para vocês, meus irmãos, que as pessoas do Islã têm estado aflitas, diante da opressão, hostilidade e injustiça causada pela aliança dos Judeus-Cristãos e pelos seus apoiadores [grifo nosso]. [...] Os massacres que tem acontecido no Tadjiquistão, Burma, Cachemira, Assam, Filipinas, Fatani, Ogaden, Somália, Eritréia, Chechênia e na Bósnia, provocam arrepios em nossas espinhas e agitam nossas paixões. Tudo isso tem acontecido perante os olhos e ouvidos do mundo, mas a flagrante arrogância imperial da América, ao abrigo da imoral Nações Unidas, tem impedido os despossuídos de se armarem. [...] Eu digo aos nossos irmãos muçulmanos em todo o mundo: seus irmãos na Arábia Saudita e na Palestina estão clamando por sua ajuda e os convidando para compartilhar com eles a jihad contra os inimigos de Deus, nossos inimigos os israelenses e os americanos [grifo nosso]. Eles estão pedindo a você para resistir a eles em qualquer maneira que você consiga, de modo a expulsá-los em defesa contra a humilhação perante os lugares sagrados do Islã. (LAWRENCE, 2005, p. 25-30).

${ }^{11}$ Termo em árabe que remete a opinião jurídica impositiva de autoridade escolástica reconhecida sobre assuntos diversos.

${ }^{12}$ Refere-se à Arábia Saudita, onde se encontram as cidades de Meca (na qual se situa a Mesquita de Haram) a cidade mais sagrada para o Islamismo, e a cidade de Medina (que contém o santuário do Profeta Maomé, e a primeira Mesquita do Islamismo, a Mesquita de Quba) a segunda cidade mais sagrada. 
Colocando-se na condição de porta-voz dos muçulmanos, Bin Laden relatava conflitos e opressões de populações islâmicas e apontava os EUA e Israel como responsáveis por essa situação, procurando internacionalizar um sentimento de hostilidade e combate a esses inimigos. Essa é a grande estratégia da Al-Qaeda: criar um sentimento global sobre os muçulmanos de ódio aos EUA e a seus principais aliados.

Posteriormente, em fevereiro de 1998, Bin Laden, juntamente com seu braço direito, Ayman al-Zahahiri e outros líderes islâmicos ${ }^{13}$, anuncia por meio da declaração "Front Islâmico Mundial" a jihad contra os Judeus e os Cruzados. Nela condena-se a política dos EUA para o Oriente Médio, qualificada de "proclamação de guerra contra Deus" (LAWRENCE, 2005, p. 60) e argumenta-se que "a jihad é um dever de todo o muçulmano quando o inimigo ataca os países islâmicos".

\begin{abstract}
Matar americanos e seus aliados - civis e militares - é um dever individual de todo o muçulmano em todos os países [grifo nosso], para libertar a Mesquita de Al-Aqsa ${ }^{14}$ e a Mesquita Sagrada ${ }^{15}$ de sua aderência, para que seus exércitos deixem todos os territórios do Islamismo, sendo derrotados, inutilizados e incapazes de ameaçarem qualquer muçulmano (LAWRENCE, 2005, p. 61).
\end{abstract}

Assim, Osama bin Laden promovia uma batalha para conquistar as mentes dos jovens muçulmanos de todo o mundo, para que eles aderissem à jihad e combatessem os infiéis. O Afeganistão tinha o importante papel de servir de local de treinamento para esses novos militantes islâmicos.

Dessa forma, de maneira semelhante ao período em que esteve situada no Sudão, a Al-Qaeda encontrou no Afeganistão as melhores condições para poder desenvolver as suas atividades de extremismo religioso. Tendo à disposição um

\footnotetext{
${ }^{13}$ Abu Yasir Rifai Ahmad Taha (Grupo Islâmico do Egito), Sheikh Mir Hamzah (Jamiat-ul-Ulema no Paquistão) e Fazlur Rahman (Movimento da Jihad em Bangladesh).

${ }^{14}$ Mesquita localizada em Jerusalém; é considerada a terceira mais sagrada do Islamismo. $\mathrm{Na}$ expressão "libertar a Mesquita de Al-Aqsa" bin Laden refere-se à libertação de toda a Palestina.

${ }^{15}$ Mesquita de Haram na cidade de Meca.
} 
território livre para estruturar suas operações, e com seu líder máximo - Osama bin Laden - desfrutando de enorme prestígio e respeito no mundo muçulmano, a organização vivia um de seus períodos mais produtivos.

No campo prático, em 7 de agosto de 1998, na data em que assinalava oito anos da instalação de tropas dos EUA na Arábia Saudita, a Al-Qaeda efetua um ousado atentado às embaixadas norte-americanas em Dar es Salaam (Tanzânia) e em Nairobi (Quênia), matando cerca de trezentas e cinquenta pessoas e ferindo mais de cinco mil.

Em outubro de 2000, a Al-Qaeda lança um bote cheio de explosivos contra o navio de guerra norte-americano USS Cole na costa do Iêmen, matando dezessete tripulantes. E em 11 de setembro de 2001, a Al-Qaeda efetua o maior atentado terrorista da História, ao sequestrar quatro aviões nos EUA tendo como alvo atingir o Pentágono, World Trade Center e a Pensilvânia matando cerca de três mil pessoas.

\section{A Al-Qaeada no pós-11 de setembro de 2001}

A invasão norte-americana em outubro de 2001 no Afeganistão enfraqueceu muito o poder da Al-Qaeda como organização territorialmente situada. Sua infraestrutura foi pesadamente atingida, muitos de seus líderes foram presos ou mortos. Seu aliado local, o Talibã, foi retirado do poder e suas fontes de financiamento (organizações não-governamentais, entidades de caridade, doadores particulares) passaram a ser fortemente vigiadas por serviços de inteligência Ocidentais.

Diante dessas novas conjunturas, a Al-Qaeda teve que se reestruturar e fortalecer sua rede de contatos através do mundo para poder continuar operando. Segundo Castells (2010, p. 135) “[...] depois da destruição do comando central da Al-Qaeda em 2001 no Afeganistão, redes de contato, com combatentes locais, tornaram-se cada vez mais importante". Essas redes de contato buscavam angariar novas fontes de financiamento, estabelecer contatos com grupos locais islâmicos, e fomentar o surgimento de células terroristas. 
Para Roy (2004, p. 294), “[...] a Al-Qaeda é uma organização e uma marca registrada. Ela pode operar diretamente, como uma join venture ou por franquia [...]". Muitos grupos estão atuando na mesma linha que ela, sem estar tendo necessariamente conexão direta com a Al-Qaeda. De acordo com Gunaratna (2004, p. 19), “[...] a Al-Qaeda evoluiu para um movimento de 24 grupos”. Ainda segundo o autor, a organização da "[...] Al-Qaeda não foi responsável pela maior parte dos ataques terroristas ocorridos depois do 11 de Setembro. Pelo contrário, estes têm sido perpetrados pelos seus grupos associados"(Ibidem). Na mesma linha de Gunartana, Castells afirma:

[...] A Al-Qaeda e Osama bin Laden, formam somente um componente do movimento, mas eles são símbolo, os papeis modelo, e o principal numa vasta e diversificada rede de grupos terroristas, alguns deles estão enraizados nos movimentos Islamistas, mas muitos são células largamente autônomas, ou organizações Islâmicas específicas de cada país.(2010, p. 110).

No estudo The evolution of Al-Qaedaism - ideology, terrorists and appel, Bakker e Boer (2007, p. 7) afirmam que a Al-Qaeda "[...] pode ser melhor descrita como um fenômeno altamente complexo e sombrio que, em termos organizacionais, parece ser um movimento ou uma 'rede de redes' e afiliados”. Neste trabalho, os autores apontam quatro principais categorias onde a "[...] presença" da Al-Qaeda pode ser constatada (2007, p. 16): “A liderança da Al-Qaeda; afiliados reconhecidos pela Al-Qaeda; autoproclamados afiliados; grupos e indivíduos que são inspirados pela Al-Qaeda, mas que não possuem ligação com a organização”.

Essa mutação estrutural da Al-Qaeda, apesar de ter sido fortemente impulsionada pelas ações de combates ocidentais lideradas pelos EUA, já estava presente na ideologia da organização. Nos textos do ideólogo Abdullah Azzam consta que a Al-Qaeda deveria desempenhar o papel pioneiro de linha de frente dos movimentos islâmicos, tendo como objetivo inspirar e instigar os grupos muçulmanos a partilhar a luta contra os inimigos infiéis.

A capacidade de atuação dos grupos associados à Al-Qaeda pode ser verificada nos atentados suicidas de 12 de outubro de 2002 contra diversos pontos turísticos na Ilha de Bali na Indonésia, efetuado pelo grupo radical indonésio Jemaah Islamiyyah 
que matou quase duzentas pessoas e deixou mais de trezentas feridas. Os atentados de 11 de março de 2004 em Madri e 7 de julho de 2005 em Londres também registram a marca da nova face da $\mathrm{Al}$-Qaeda. Em ambos os casos, os terroristas envolvidos não possuíam subordinação direta com o grupo de Osama bin Laden, atuavam em células terroristas independentes e utilizaram a Al-Qaeda como fonte de inspiração.

As células da Al-Qaeda normalmente são pequenas e formadas por indivíduos regularmente inseridos no local onde se encontram. Eles mantêm certo contato com a organização, mas geralmente atuam por conta própria improvisando, buscando recursos e tomando suas próprias iniciativas. Sua especificidade e efetividade estão justamente no seu elevado grau de autonomia.

Para Castells a "[...] autonomia é elevada em virtude da simplicidade dos objetivos, e por causa do místico caráter da organização, inteiramente devota à vontade de Deus, minimizando assim problemas de disciplina" (2010, p. 137). A organização em células também cria dificuldades para os Estados rastreá-las e combatê-las. Os EUA puderam bombardear algumas bases operacionais da Al-Qaeda no Afeganistão, mas jamais poderiam bombardear a cidade de Hamburgo, onde o 11 de Setembro foi preparado (CASTELLS, 2010, p. 138).

Dessa forma, sem poder mais contar com uma base fixa, a Al-Qaeda dividiu-se em pequenas células, embora continue atuando por meio de seus grupos associados. Para Castells (2010, p. 136-137) “[...] esse caráter dual de lutas locais e redes de contatos globais é a essência da estratégia da Al-Qaeda na situação do pós-guerra afegã’. Atuando dessa maneira, o grupo pode mais facilmente botar em prática sua ideia de atacar seus alvos a qualquer momento e em qualquer lugar.

Dentro do processo evolutivo da Al-Qaeda, a principal mudança estrutural ocorreu na transformação de grupo, de realizador de atentados terroristas para fomentador e inspirador dos ataques. Para Amorim (2008, p. 104) “[...] seu nome [Al-Qaeda] vem sendo utilizado por diversos grupos ao redor do mundo a fim de obter simpatizantes para a causa, recrutas e recursos financeiros, bem como buscar uma legitimidade jihadista, tornando-se assim uma franquia do terror". A Al-Qaeda evoluiu para uma rede de amparo a extremistas islâmicos, troca de expe- 
riências, financiamentos, que opera como uma organização secreta, quase virtual, alcançando o perigoso status não somente de grupo terrorista transnacional, mas também de ideologia para os muçulmanos radicais.

O termo "ideologia" não é exagerado, como podemos também observar pelo lançamento das revistas de propaganda Inspire "Disponibilizadas gratuitamente na internet em língua inglesa a partir de 2010, elas se configuram em incríveis manuais para a divulgação do Islamismo radical. Usando uma linguagem acessível, as edições da Inspire trazem entrevistas com os principais líderes da Al-Qaeda, reportagens que analisam desde a proibição do véu islâmico na França, até o aquecimento global e dicas de como utilizar a internet para mandar mensagens criptografadas, entre outras questões.

A revista também gera publicidade a antigos comandantes da organização como o egípcio Ayman al-Zawahiri, e para novos líderes como o sírio Shaykh Abu Basir, e o norte-americano de descendência iemita, Anwar al-Awlaki. Como o próprio nome afirma, essas revistas visam inspirar os muçulmanos a lutar pela causa da Al-Qaeda.

Desse modo, a Al-Qaeda cria condições para que qualquer pessoa, inclusive aquelas que nunca contataram nenhum membro da organização, possam realizar atentados por conta própria em nome da jihad. As sessões "make a bomb in the kitchen of your mom" (Inspire $\mathrm{n}^{\circ} \mathrm{I}, 2010$, p. 33-40,)," the ultimate mowing machine" (Inspire no II, 2010, p. 53-54) ensinam passo a passo como efetuar atentados, utilizando técnicas relativamente simples. Atuando menos como organização e mais como inspiração para seus grupos associados e para todo e qualquer muçulmano, a Al-Qaeda conseguiu desenvolver uma maneira de terceirizar suas atividades a qualquer um que se sinta motivado a engajar-se na jihad, podendo reivindicar o perigoso e complexo status de ideologia.

\section{A Ai-Qaeda pós Bin Laden}

Para melhor entender o impacto da recente morte do fundador da Al-Qaeda, Osama bin Laden, é preciso contextualizá-la com a situação organizacional atu- 
al da Al-Qaeda e visualizá-la não como uma organização estática, mas sim como uma ideologia do radicalismo islâmico e um conjunto de redes e grupos afiliados.

A organização evoluiu conforme o conceito original proposto por Azzam no final dos anos 1980: o estabelecimento de uma vanguarda dentro do pensamento islâmico. Além de uma organização funcional que combata os inimigos do Islamismo, a Al-Qaeda deveria servir de modelo e inspiração para toda a sociedade muçulmana, mobilizando assim novas gerações a lutar pelos princípios do Islamismo.

Como procuramos apresentar ao longo deste trabalho, a Al-Qaeda alterou consideravelmente seu modus operandi desde o início da ofensiva político-militar “Guerra ao Terror", dos EUA, em outubro de 2001. Nos últimos dez anos, a organização esteve fortemente sob investigação dos serviços de inteligência ocidentais, e seu líder máximo, Bin Laden, teve por conta disso, uma expressiva perda de sua liderança operacional.

Para Merlos (2006, p. 10), os principais quadros da Al-Qaeda, entre eles Bin Laden, “[...] estão em uma situação de isolamento e cerco". Ainda segundo o autor (Idem. p. 10-11) “[...] apesar de tratar-se dos membros mais veteranos e com maior experiência de combate, sua margem de manobra exibiu-se muito reduzida e também sua capacidade para ordenar atentados de envergadura”.

A descentralização das atividades da Al-Qaeda e suas atuações por meio de grupos afiliados, ou por indivíduos ou organizações inspiradas por ela, demonstram a redução da atuação de Bin Laden. Esses grupos que atuam sob o rótulo da Al-Qaeda muitas vezes nem realizam contato direto com a liderança da Al-Qaeda.

Segundo Bakker e Boer (2007, p. 20) nos grupos que se autoproclamam afiliados da Al-Qaeda “[...] sua ligação com a Al-Qaeda é indireta - e alguns casos ambos os lados podem nem sequer ter conhecimento de qualquer ligação entre os indivíduos dentro de sua rede”. Já os grupos e indivíduos inspirados pela Al-Qaeda, ainda de acordo com Bakker e Boer (2007, p. 21) “[...] trata-se de pequenos grupos e indivíduos sem vínculos diretos com a liderança da Al-Qaeda, ou até mesmo sem nenhuma ligação com nenhum membro". 
Um exemplo da atuação de indivíduos inspirados pela Al-Qaeda pode ser observada atualmente na influência do pensamento do clérigo radical Anwar al-Awlaki (frequentemente citado na revista Inspire da Al-Qaeda). Ele é acusado pelo governo dos EUA de ter direta ou indiretamente motivado o Major norte-americano de origem jordaniana, Nidal Malik Hasan, a iniciar um tiroteio na instalação militar de Fort Hood, no Texas, em novembro de 2009, que resultou na morte de 13 militares norte-americanos. Awlaki também é acusado de inspirar o nigeriano Umar Farouk Abdulmutallab que tentou explodir o voo 253 da Delta Airlines sobre Detroit em 25 de dezembro de 2009 (CONGRESSIONAL RESEARCH SERVICE, 2011, p. 16).

Para Merlos (2006, p. 2):

[...] é justamente a dificuldade dos serviços de inteligência em determinar onde termina hoje a Al-Qaeda e onde começam as organizações que operam de forma mais ou menos independentes, que certamente ampliam e distorcem o poder e a capacidade de manobra reais de Osama Bin Laden e da velha cúpula árabe-afegã.

Nesse sentido, em razão da forte descentralização das atividades coordenativas da Al-Qaeda, a efetividade de Bin Laden como gerenciador de tarefas mostrou-se muito reduzida. Assim, sua morte pouco modifica a engrenagem das atividades terroristas islâmicas mundiais. Durante o tempo em que esteve frente a Al-Qaeda (sobretudo no período pós-11 de Setembro), sua grande contribuição para a organização consistia em seus discursos mobilizadores e na elevada atração que seu nome e sua história possuíam entre os extremistas islâmicos.

Com sua morte, o que temos é a consolidação de sua imagem perante os muçulmanos radicais, agora sob a tintura de mártir. A perda do líder espiritual da Al-Qaeda provavelmente intensificará o processo, de transformação da Al-Qaeda, de uma organização estática e hierarquizada em um movimento de inspiração de grupos e indivíduos extremistas islâmicos, iniciado após a invasão americana no Afeganistão, em 2001.

Não haverá mais novos discursos de Bin Laden, mas é muito provável que os antigos ganhem ainda mais força em razão da ausência de seu autor. Porém, essa 
constante pluralidade das atividades da Al-Qaeda tem permitido aos grupos que se associam direta ou indiretamente, impor suas próprias demandas e objetivos.

Com isso, a morte de Bin Laden pode representar duas situações para o futuro ideológico da Al-Qaeda. A primeira é a consolidação da Al-Qaeda como um conjunto de redes de contatos entre extremistas islâmicos e fonte de inspiração para radicais muçulmanos. Atuando em seus próprios territórios, mas sob a bandeira dos ideais da Al-Qaeda, esses grupos e/ou indivíduos combinarão suas próprias demandas com a ideologia da Al-Qaeda.

Por outro lado, a forte descentralização da Al-Qaeda pode resultar em uma perigosa fragmentação do grupo, na qual, as organizações afiliadas, por terem cada vez menos contato direto com a liderança da Al-Qaeda, desenvolvam suas próprias dinâmicas e se afastem do pensamento da Al-Qaeda. Mesmo sob o rótulo ou inspiração da Al-Qaeda, esses grupos podem evoluir para uma posição independente em relação a essa organização. Grupos inspirados pela Al-Qaeda são, ao mesmo tempo, inspirados por uma série de outros líderes, ideologias e lutas (BAKKER e BOER, 2007, p. 21)

No campo operacional de ataques terroristas, o falecimento de Bin Laden tende a não alterar a atual dinâmica das ações terroristas de escala global. O próprio Osama bin Laden tem historicamente reachado a ideia de se situar como comadante-chefe de todos os grupos terroristas islamistas que se opunham, antes mesmo do 11 de Setembro, à influência ocidental no Oriente Médio (MERLOS, 2006, p. 2).

A morte do saudita provavelmente motivará os partidários do Islamismo radical a praticarem atos de violência em sua memória. Isso deve ocorrer essencialmente em curto prazo, como observamos no recente atentado a uma academia militar no norte do Paquistão, no último dia 13 de maio, reivindicado pelo movimento Talibã paquistanês, no qual, cerca de 88 pessoas morreram e 105 ficaram feridas. ${ }^{16}$

\footnotetext{
${ }^{16}$ Site Uol de Notícias: <http://noticias.uol.com.br/ultimas-noticias/efe/2011/05/13/talibas-dizem-que-atentado-no-paquistao-e-vinganca-pela-morte-de-bin-laden.jhtm>.
} 
A provável conjuntura para os próximos anos é da manutenção dos atentados terroristas que vêm ocorrendo de forma esporádica, mas ininterruptamente, no mundo, sobretudo em países onde a presença norte-americana ainda ocorre (Afeganistão e Iraque) e em Estados muçulmanos aliados aos EUA (Arábia Saudita, Iêmen e Paquistão).

\section{Conclusão}

Acompanhando sua ideologia, a Al-Qaeda foi se alterando no decorrer dos anos. A organização, que no primeiro momento era razoavelmente estruturada, territorialmente situada e comandada diretamente por Osama bin Laden, evoluiu para uma categoria que atualmente se aproxima dos desejos de Azzam: uma franquia do Islamismo radical.

Sua força está no poder de inspiração que a "marca" Al-Qaeda representa atualmente. A morte de Bin Laden para a Al-Qaeda operacionalmente não representa muitas mudanças para a organização. Desde os eventos do 11 de Setembro, o saudita tinha concentrado seus esforços mais em escapar dos serviços de inteligência dos EUA do que conspirar de forma prática contra essa nação e seus aliados.

Como a própria natureza da Al-Qaeda permite e incentiva que operações de ataques sejam desenvolvidas e realizadas por células independentes e até mesmo por cidadãos comuns que, de alguma forma, sintam-se motivados pelos ideais da Al-Qaeda, a ação em si de Bin Laden era apenas uma entre as inimagináveis possibilidades de ataques que a organização dispõe.

Consolidado como um movimento de pensamento radical, mais do que como uma organização estruturada, a força da Al-Qaeda está no seu grau de penetração nas ideias dos muçulmanos. Nesse sentido, Bin Laden era apenas o rosto mais conhecido dos incentivadores dessa visão de mundo intolerante. Como foi dito, outros líderes continuam a divulgar os ideais da Al-Qaeda e inspirando jovens muçulmanos a cometer atentados. A passagem de Bin Laden para a História com certeza o transformará em mártir e seus discursos passados ainda 
ganharão mais força dentre seus adeptos; ela não representa o fim da ideologia da Al-Qaeda.

Porém, a morte de Bin Laden pode também levar a uma maior fragmentação da Al-Qaeda como organização e como conjunto de ideias. A atual descentralização do grupo pode evoluir para situação que, tendo mais poder e eficiência como "marca registrada" do que como organização estruturada, os próprios ideais da Al-Qaeda sejam suplantados em vista das demandas locais dos grupos que a utilizam como inspiração.

A batalha contra o extremismo islâmico não é uma luta física travada em territórios, mas um conflito no campo das ideias, que tem como origem um pensamento muçulmano radical e intolerante construído dentro de um contexto de opressão dos muçulmanos e fomentado, direta ou indiretamente, pelas grandes potências ocidentais.

\title{
The death of Osama Bin Laden and its implications for Al-Qaeda's future
}

\begin{abstract}
This article aims to undertake a historical and sociological investigation of Al-Qaeda, analyzing its constituent ideals as well as its development track record to date. We seek well be able to identify and trace the possible trends of behavior of the organization without the presence of its leader, Osama bin Laden. We conclude that Al-Qaeda in contemporary acts more as a source of inspiration for radical Islamic groups than as a strict organization, and accordingly the death of Bin Laden slightly weakens the operation of the group.
\end{abstract}

Keywords: Al-Qaeda. Radical islamic thought. Osama bin Laden. 


\section{REFERÊNCIAS}

ALI, Mohannad Hage; CRUICKSHANK, PauL. Abu Musab Al Suri: Architect of the New Al Qaeda. In: Studies in Conflict \& Terrorism, 30:1-14, 2007.

AMORIM, Alexandre Santos de. A globalização do radicalismo islâmico: um estudo de caso da Al-Qaeda sob a luz do Choque de Civilizações. 2008. 121f. Dissertação (Mestrado em Relações Internacionais) - Universidade de Brasília, Brasília, 2008.

BAKKER Edwin; BOER, Leen. The evolution of Al-Qaedaism: Ideology, terrorists, and appeal. Den Haag: Netherlands Institute of International Relations Clingendael, 2007.

BERGEN, Peter L. Holy War, Inc.: Inside the Secret World of Osama bin Laden. New York: The Free Press, 2001.

BURKE, Jason. Al-Qaeda: A verdadeira história do radicalismo islâmico. Rio de Janeiro: Jorge Zahar, 2007.

CASTELLS, Manuel. The power of Identity, the Information age: economy, society and culture. 2. ed. v. 2. Cambridge, MA; Oxford, UK: Blackwell, 2010.

FERNÁNDEZ, Haizam Amirah. ¿Tiene Al-Qaeda una estrategia global? In: Elcano Royal Institute Analyses, ARI No 74/2004, 20 abr. 2004. Disponível em: <http:// www.xlugh.com/islamnews/docs/estrategia.pdf>. Acesso em: 15 abr. 2011

FILIU, Jean-Pierre. Al-Qaeda, entre la dinámica paquistaní y la tentación virtual. In: Elcano Royal Institute Analyses, ARI No 4/2010, 15 jan. 2010. Disponível em: $<$ http://www.realinstitutoelcano.org/wps/portal/rielcano/contenido?WCM_ GLOBAL_CONTEXT=/elcano/elcano_es/zonas_es/terrorismo+internacional/ ari4-2010>. Acesso em: 18 abr. 2011.

FOSTER, Michel; SAWYER, Reid. The Resurgent and Persistent Threat of al Qaeda. In: The ANNALS of the American Academy of Political and Social Science, 2008. Disponível em: <http://www.ctc.usma.edu/wp-content/uploads/2010/06/ The-Resurgent-and-Persistent-Threat-of-al-Qaeda.pdf >. Acesso em: 3 maio 2011.

GUNARATNA, Rohan. No interior da Al-Qaeda, rede global do terror. Lisboa: Relógio D’Água Editores, 2004.

. Al Qaeda's ideology. In: HILLEL FRADKIN et al. (Eds.), Current trends in islamist ideology. Washington, D.C.: Hudson Institute, p. 59-67, 2005. 1 v. 
INSPIRE. Península Arábica. Al-Malahem Media. Verão de 2010. Península Arábica. Al-Malahem Media. n. 2, 2010.

LAWRENCE, Bruce. Messages to the World: The Statements of Osama bin Laden. Londres: Verso, 2005.

JONES ,David Martin.; SMITH, Michael L. R.; WEEDING, Mark. Looking for the Pattern: Al Qaeda in Southeast Asia - The Genealogy of a Terror Network. In: Studies in Conflict \& Terrorism, n 26, 2003, p. 443-457.

KEPEL, Gilles. Jihad: expansão e declínio do islamismo. Rio de Janeiro: Biblioteca do Exército, 2003.

KOWERT, Paul.; KUBALKOVA, Vendulka, ONUF, Nicholas. International Relations in a Constructed World. Armonk: M.E. Sharpe, 1998.

MERLOS, Alfonso. La deconstrucción de Al Qaida: de la jerarquía al yihadismo individualizado. Conferencia pronunciada en las Jornadas "La nueva situación en Oriente Próximo: estabilidad, negociación y terrorismo". Universidad Pontificia de Salamanca, 15 al 17 de noviembre de 2006. Disponível em: <http://www.ugr. es/ terris/deconstruccion.pdf $>$. Acesso em: 30 abr. 2011

MESSARI, Nizar; NOGUEIRA, João Pontes. Teoria de relações internacionais: correntes e debates. Rio de Janeiro: Elsevier, 2005.

MISHAL, Shaul. ROSENTHAL, Maoz. Al Qaeda as a Dune Organization: Toward a Typology of Islamic Terrorist Organizations. In: Studies in Conflict \& Terrorism, 28, p. 275-293, 2005. Disponível em: <http://www.isn.ethz.ch/isn/ Digital-Library/Publications/Detail/?ots591=0C54E3B3-1E9C-BE1E-2C24A6A8C7060233\&lng=en\&id=46602>. Acesso em: 21 abr 2011.

PACE, Enzo. Sociologia do Islã: fenômenos religiosos e lógicas sociais. Petrópolis: Vozes, 2005.

ROLLINGS, John. Al-Qaeda and Affiliates: Historical Perspective, Global Presence, and Implications for U.S. Policy. Congressional Research Service. 25 jan. 2011. Disponível em: <http://fpc.state.gov/documents/organization/156542.pdf>. Acesso em: 23 abr 2011.

ROY, Oliver. Globalized Islam: the search for a new ummah. Washington: Columbia University Press, 2004. 
Univ. Rel. Int., Brasília, v. 9, n. 2, p. 139-160, jul./dez. 2011
Bruno Mendelski de Souza

SAGEMAN, Marc. Understanding terror networks. Pennsylvania: University of Pennsylvania Press, 2004.

STERN, Jessica. Terror em nome de Deus: por que os militantes religiosos matam. São Paulo: Barcarolla, 2004.

TALIBÃS dizem que atentado no Paquistão é vingança pela morte de Bin Laden. UOL Notícias. 13 mai. 2011. Disponível em: <http://noticias.uol.com.br/ultimasnoticias/efe/2011/05/13/talibas-dizem-que-atentado-no-paquistao-e-vingancapela-morte-de-bin-laden.jhtm>. Acesso em: 23 abr 2011.

WIKTOROWICZ, Quintan. A genealogy of radical Islam. In: Studies in Conflict \& Terrorism, n.28, p. 75-97, 2005. 